\title{
Cultural Change, Human Activity, and Cognitive Development
}

\author{
Mary Gauvain $^{\mathrm{a}}$ Robert L. Munroe ${ }^{\mathrm{b}}$

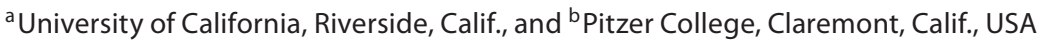

\author{
Key Words \\ Cognitive assessment • Cognitive development • Cross-cultural psychology • \\ Naturalistic observations $\cdot$ Societal change
}

\begin{abstract}
Differential cognitive performance across cultural contexts has been a standard result in comparative research. Here we discuss how societal changes occurring when a small-scale traditional community incorporates elements from industrialized society may contribute to cognitive development, and we illustrate this with an analysis of the cognitive performances and everyday activities of children from four communities representing a range of such incorporations. We discuss this research in relation to ontogenesis and sociogenesis and propose several processes or mechanisms that may account for cultural and cognitive change in the context of societal absorption of elements common in industrialized settings. Our perspective centers on the claim that changes in cultural features are inextricably linked to changes in human activity and cognition. We also suggest that changes that align small-scale traditional societies in this way provide certain cognitive advantages for individuals raised in, and continuing to live in, traditional societies, and such advantages show up in many cognitive measures. We also use this information in discussing explanations for the Flynn effect. We conclude with consideration of some implications of the perspective we offer.
\end{abstract}

Copyright $\odot 2012$ S. Karger AG, Basel

In a recent article, we presented the results of a cross-cultural study of children's cognitive performance [Gauvain \& Munroe, 2009]. Overall, the study showed that differential societal modernity, defined as the presence in small-scale traditional societies of various appurtenances common to industrial and post-industrial societies, was associated with better performance on a suite of cognitive tests. Since then, sim-

\begin{tabular}{ll}
\hline KARGER & ( ) 2012 S. Karger AG, Basel \\
0018-716X/12/0554-0205\$38.00/0 \\
$\begin{array}{ll}\text { Fax +41 61 306 12 34 } \\
\text { www.karger.com }\end{array}$ & $\begin{array}{l}\text { Accessible online at: } \\
\text { www.karger.com/hde }\end{array}$
\end{tabular}

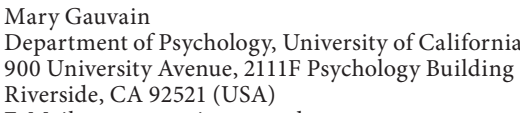

Department of Psychology, University of Californi 900 University Avenue, 2111F Psychology Building Riverside, CA 92521 (USA)

E-Mail mary.gauvain@ucr.edu 
ilar findings have emerged from analyses of the same dataset, and we describe these outcomes below. Our general conclusion is that the sum of results says something meaningful about cultural differences in cognitive functioning, and we critique the often-held viewpoint that any such differences must be questioned due to various difficulties in cross-cultural comparison. Nevertheless, in thinking through our original interpretation as to the beneficial effects of modernization, we have come to a more nuanced position, one which does not, like the first interpretation, see modernity as an 'independent variable' and cognition as the 'dependent variable,' but which instead adopts a view that tries to show how changes in cultural features are inextricably linked to changes in human activity and cognition. We begin by specifying our current framework, which at its core is informed by the sociocultural approach to cognitive development.

\section{The Sociocultural Approach to Cognitive Development}

The sociocultural approach views children's learning and cognitive development from the vantage point of historically situated activities that are mediated by symbolic and material artifacts, such as language and technology, and societal institutions of the culture in which growth occurs [Cole, 1996; Göncü \& Gauvain, 2012; John-Steiner, 1985; Rogoff, 2003; Valsiner, 2000; Vygotsky, 1987; Wertsch, 1985]. This approach emphasizes the contributions to cognitive development from peers, kin, and other adults in the community, which create opportunities for learning through social psychological processes such as modeling, instruction, guidance, and shared activity. These opportunities, which are explicitly and implicitly arranged to fit with the developmental and individual needs of children, occur in formal and informal settings and permeate the activities in which children engage on their own and with others.

When children participate in cultural activities, they are introduced to conventional ways of thinking and acting. Cognitive development is not determined by these experiences, however. The social world is a dynamic and mutually generated context in which children are active participants. Thus, children do not passively assume the cultural conventions that are introduced to them over the course of socialization [Gauvain \& Perez, 2007]. Rather, cognitive development emerges from the transactions children have with the symbols, tools, and members of their culture. In other words, these transactions do not simply expose children to external stimuli to which they learn to respond; they carry cultural meaning and as children engage in activities they construct, negotiate, and then carry forward this newly acquired meaning in their own actions. This process happens when the child works alone or with another person or persons aided by the tools and artifacts of the culture. It is a microgenetic process in that learning emerges over a certain period of time in a particular context. During learning children adopt, adapt, discard, or replace the conventional ways of thinking and acting of their culture.

It is in this way that culture and mind, including the developing mind of the child, are mutually constituted [Nucci, Saxe, \& Turiel, 2000]. Together they create change at various levels of human experience: in understanding as it emerges during an activity, or microgenetic change, in individual development over the lifespan, or ontogenetic change, and in the social group, or sociogenetic change [Greenfield, 2004; Saxe, 2008]. Whereas microgenesis and ontogenesis occur in the individual, sociogenesis occurs in 
the social or cultural group and, therefore, it transcends the individual both in contemporary experience and, historically, when transmitted across generations. In this paper, we concentrate on ontogenetic and sociogenetic change, but we stress that microgenetic change is the kernel or core of the human learning system.

\section{Ontogenesis and Sociogenesis: Individual Development and Societal Change}

This paper is concerned with how changes in children's thinking over childhood (ontogenesis) and changes in society (sociogenesis) inform and transform one another. Both Greenfield [2004] and Saxe [2008] described the concordance of these two levels or types of developmental change in accounts of their return visits after long absences to the small-scale traditional communities where they had previously conducted research. For both researchers, dramatic changes occurred in the indigenous practices they had observed on earlier occasions.

On visiting the Mayan community in Chiapas 25 years after she conducted her initial research on traditional weaving practices, Greenfield [2004] found that weaving had changed in form and process. In terms of form, the number of woven patterns had expanded considerably and mostly contained the bright colors and floral and other designs that were now favored by the community. Regarding process, the traditional way of learning how to weave was largely observational and involved daughters sitting beside their mothers and watching them weave over a lengthy learning period, often many years. This process had been replaced by older girls, typically a sister, teaching younger girls how to weave, with less modeling and guidance, and more trial-and-error learning. Greenfield argued that both of these shifts represented adaptations to increased engagement in a market economy, one in which weavers wove garments to sell people both inside and outside the village.

Saxe $[1977,1979]$ had studied indigenous mathematics practices in a remote village, the Oksapmin community, in Papua New Guinea. On returning 25 years later, he, too, observed substantial change in the practices he originally observed. The 27part body counting system Saxe had initially observed was the way in which the Oksapmin enumerated and communicated amounts; for example, if someone pointed to the 14th body part in the 27-part sequence, which was the nose, the person conveyed that there were 14 items (e.g., objects, people) in a set. However, when Saxe returned in 2001, he discovered that community members had new methods that allowed them to communicate multiples of amounts. These methods were integrated with the body counting system; for example, if an individual stated a particular term ( $f u$ ) after touching a body part, it would signify that the number indexed by the body part should be doubled. On investigating the reasons for this change, it was discovered that the villagers had become involved in a cash economy that made these arithmetic procedures necessary and, important for our discussion, that these procedures had become codified in new linguistic and communicative forms [Saxe \& Esmonde, 2005]. These observations led Saxe [2008] to examine the relation between ontogenesis and sociogenesis, focusing on the origins of social or collective representations, specifically how 'historical changes in collective forms of representation come to be used by individuals in communication and problem-solving activities' (p. 86). 
For both Greenfield [2004] and Saxe [2008], ontogenesis and sociogenesis are separate but intertwined processes of human development. In their research, economic change was the driving force behind the cognitive and cultural changes they observed. In making a similar point, other research has pointed to schooling as a large-scale social change that is pivotal in shaping cognitive development [e.g., Gay \& Cole, 1967; Serpell, 1979; Stevenson, Parker, Wilkinson, Bonnevaux, \& Gonzalez, 1978; Wagner, 1978]. We do not dispute that economic changes and the introduction of formal school in a community can be huge forces of cultural and cognitive change. However, we contend that sociogenesis is often very broad in scope and affects many facets of life and learning in a community, including the daily activities and social and institutional transactions in which adults and children engage.

In an effort to describe this process, we focus on changes to human activity and cognitive development as communities incorporate the technology, practices, and institutions common in industrial and postindustrial societies. Although such changes typically involve greater engagement in a cash economy and formal schooling, they also include other changes such as switching from candle power to electricity (which means people can now do more things or different types of things in a day), the establishment of institutions in addition to schools (such as post offices and social gathering places that offer different ways of interacting and with garnering resources [employment]), different forms of transportation (which may make distances from the workplace or from kin less of a problem), changes in daily activities devoted to subsistence such as methods of heating and of cooking food (which may involve shifting from a more hazardous method, e.g., open-fire cooking, to a less hazardous method, e.g., kerosene stoves, which can positively affect children's health [Munroe \& Gauvain, 2012]), and a home-based water supply (which frees up time previously devoted to locating, fetching, transporting, and purifying water, as well as lowering health risks associated with contaminated water). We are not only interested in the presence of these elements in a household, but also in their presence in the community at large. In our view, every household does not need to have certain elements for a community to be transformed by a new practice.

We are also interested in the processes or mechanisms that account for changes in culture and cognitive development during sociogenesis. In any situation, there are likely several mechanisms at play, and they may be interrelated; for example, formal schooling and a cash economy tend to co-occur. Some mechanisms are more aligned with societal features, such as economic and schooling changes, and some may be social psychological in nature, such as how knowledge is organized and distributed in a community. In our discussion, we offer some ideas regarding mechanisms that may underlie the cultural and cognitive changes in the data we use for illustration of our points. In this discussion, we are mindful that sociogenesis requires different types of mechanisms than ontogenesis does [Saxe \& Esmonde, 2005], and here we are aided by sociocultural theory. As Saxe [2008] pointed out in reflections on an earlier paper by Wertsch [1979], Vygotsky's ideas about cultural mediation in cognition and cognitive development provide a mechanism as to how changes in culture become part of the social histories of a community and are, in turn, instantiated in ontogenesis through the collective forms of representation and activity in which learning and cognitive development occur and are expressed. Recall that Saxe used this framework in his account of changes in counting and mathematics in the Oksapmin community where he located sociogenesis in the reproduction and altera- 
tion of prior forms of representation as individuals engage as interlocutors in collective practices ... In their efforts to get across intended meanings, people unintentionally drew on prior representational forms, using them in new ways. An unintended consequence of such local communicative efforts was that it seeded the propagation of new forms of communication' (p. 86).

Although we concentrate on institutions and other elements, including technology, associated with industrial and postindustrial societies, it is important to stress that our research was not informed by what is known as classic modernization theory, a controversial view that dominated in the mid-20th century and relied on untested and value-laden assumptions, and very likely reflected a Western bias of that era [Kagitçibasi, 1998]. Because classic modernization theory presumed social progress, it also assumed that the adoption of modern elements would lead to improvements in cognitive performance. However, the performances assessed reflected cognitive skills practiced and valued in Western - and typically more 'modern' - cultures as opposed to the traditional cultures that were the focus of comparison, which inevitably raised questions about the validity of these measures among non-Western peoples. There is also a contentious debate as to whether the adoption of features common in industrial societies is beneficial. Although some such changes may be beneficial, for example, improved health care, others may be regressive or destabilizing, such as increased trade that exposes the population to economic disparity or new diseases.

Our take regarding the incorporation of elements of industrial societies in traditional small-scale communities is pragmatic and stems from the recognition that the process that is sometimes referred to as modernization includes a set, oftentimes a pattern, of change that is a continuing societal force likely to relate in significant ways to psychological development. Thus, in our view, research is needed that recognizes the complexity of such change while at the same time avoiding untested assumptions of earlier eras. In our research, we examined a particular sort of societal change and cognitive development without presuming positive relations or outcomes. The broader issue of globalization is of direct relevance to our inquiry in that one of the principal features of globalization is exposure to and integration of technological and other forms of change typically encountered in industrialized settings.

So, to be clear, we do not use the terms 'modern' or 'modernization' here; we have opted for a more neutral connotation and refer to the societal changes that are the focus of our discussion as emblematic of industrialized communities. As to the term 'small-scale traditional,' its use here is in the interest of adopting a conventional, easily understood label for peoples whose sociocultural history was not, for a long time, a part of the industrial trajectory. Other terms like 'tribal,' 'non-Western,' 'indigenous,' or 'ethnic group' have been used, and they too are problematic in various ways. But the label 'small-scale traditional' continues to be employed in cross-cultural research [Callaghan et al., 2011], and we do so in this article.

\section{Children's Activities and Cognitive Performance in Relation to Societal Changes in Four Small-Scale Traditional Communities}

Cultures change continuously and there are many sources of change. Here we concentrate on one particular pattern of change that is evident to varying degrees in the increasing global landscape, specifically the adoption of the technology, institu- 
tions, and social practices that are common in industrialized communities. We assert that these cultural changes are inseparable from cognitive processes and their development. Thus, like Nucci et al. [2000], we reject the unidirectional notion that culture determines cognition and, instead, we stress the dynamic, contextual and transactional nature of human cognition and culture.

By way of illustration, we discuss data collected in the late 1970s in four smallscale traditional communities that underwent, to varying degrees, changes in societal features as they adopted the technologies, institutions, and practices common to industrialized societies [Munroe \& Munroe, 1990a, 1990b, 1991; Munroe, Munroe, Shwayder, \& Arias, 1997]. Although these data are archival, we consider this an advantage for our purposes. It so happens that the processes we want to study may benefit through being viewed from a historical distance. It is also the case that the sweep of changes in which we are interested is increasingly difficult to study because a large number of people and communities around the world today have already adopted many of these accoutrements. Even people living in geographically isolated communities are adopting the tools and artifacts of industrialized societies, such as cell phones.

These data are cross-sectional and not longitudinal. Thus, we are using patterns across cultures at the same point in time as a way of examining cultural and cognitive change. A longitudinal analysis is, of course, preferable. But given that the processes of change we are trying to describe typically occur over a lengthy period of time, emerge in piecemeal fashion, and occur somewhat organically - that is, they emerge from the community - they can be difficult to study. As a result, we opt for a substitute method, using archival data in a cross-sectional analysis, in the hopes of describing an intersection of onto- and sociogenesis.

\section{Children's Cognitive Performance in Relation to the Incorporation of Elements Common in Industrialized Settings}

As noted, in a recent article, we analyzed and interpreted cultural differences in cognitive performance among young children [Gauvain \& Munroe, 2009]. In the present article, we discuss what we believe to be some of the implications of our findings and, by extension, the possible implications for understanding the relation between ontogenesis and sociogenesis. We are particularly interested in the incorporation by small-scale traditional communities of various features of industrialized societies. Such incorporation can affect, on a daily basis, the work people do, the way children are cared for and educated, and the nature and strength of the links between the community and the world beyond the community. As a society adopts more of these resources and practices, children are exposed to changing modes of acting and interacting both inside and outside the home and, as a result, these community changes have direct relevance to processes of human development, including cognitive growth.

We begin by briefly summarizing the results and interpretation of our crosscultural research [Gauvain \& Munroe, 2009]. The sample was comprised of a total of 192 3-, 5-, 7-, and 9-year-olds spread evenly among four cultural communities that differed in their incorporation of elements from industrial societies at the time the data were collected. We followed the sociocultural view by investigating how the 
availability of cultural tools supports cognitive development, a point emphasized by Vygotsky [see Daniels, Cole, \& Wertsch, 2007]. We measured the possession of communicative and literacy-based appurtenances and other resources that are typical in industrial societies, including writing tablets and books, the availability of electricity, a home-based water supply, radio and television sets, and ownership of a motor vehicle.

The four communities, representing Garifuna in Belize, Logoli in Kenya, Newars in Nepal, and Samoans in American Samoa, differed geographically and linguistically and, at the time of data collection (1978-1979), had no contact with each other. The children were administered seven standard cognitive measures under conditions controlled by the same researcher (the late Ruth H. Munroe), who trained and supervised local experimenters. Of these measures, five, the Group Embedded Figures Test [Oltman, Raskin, \& Witkin, 1971], block building (Wechsler Preschool and Primary Scale of Intelligence) [Wechsler, 1963], motor coordination, perspective-taking skill [Masangkay et al., 1974], and gender understanding [Slaby \& Frey, 1975], were designed and administered similarly to research conducted in Western settings. Two measures, a memory recall task [patterned after Grusec \& Brinker, 1972] and a task that assessed the child's willingness to explore novel objects, were adapted to the cultural setting by using materials and depicting scenes that were familiar to children in each setting.

The findings replicated typical age-related improvements in cognitive performance, and these findings were evident on the five tasks that were similar to those conducted in Western settings and also on the two tasks that were adapted to the specific cultural setting. Community adoption of elements from industrial societies, scored both individually (e.g., radios in the home) and at the community level (e.g., postal stations, commercial accommodations), predicted better performance on all measures. In general, the communities that had adopted more of these elements, American Samoans and Garifuna, outperformed the Newar and Logoli children, and the rank correlation between community adoption and overall cognitive performance was perfect. (Traditional complexity of culture, as exemplified by the Newars' sophisticated rice irrigation system and their syncretistic Hindu-Buddhist religion, was unassociated with cognitive performance.) Schooling was associated with good test performance, but societal adoption of these elements was about equally strong as a predictor. Furthermore, the superior cognitive performance of Samoan and Garifuna children showed up among even unschooled 3-year-olds.

\section{Children's Cognitive Performance and Open-Fire Cooking}

In the subsequent analysis of the four-culture sample, we reexamined these same data in light of recent research that shows open-fire cooking - with its emission of harmful substances - to pose a risk to healthy physical development [Munroe \& Gauvain, 2012]. Open-fire cooking exposes children to harmful substances such as carbon monoxide (CO), which, in turn, makes children susceptible to respiratory ailments, weakens their immune system, and can lead to pneumonia, the leading cause of death among young children worldwide [McCracken et al., 2009; Smith, Mehta, \& Maeusezahi-Feuz, 2004]. The health risk is especially high among children 3 years of age and younger, reflecting changes to the brain and other organs, such as 
the lungs, during this age period [Couperus \& Nelson, 2006]. Young children may also be at higher risk relative to older children because they spend more time in and around the home area where the open fires burn [Munroe et al., 1997; Munroe \& Munroe, 1990a, 1990b, 1991].

Despite extensive research on the effects of open-fire cooking on children's physical health and development, there has been little investigation of how this exposure may relate to cognitive development. To address this topic, we studied the relation between exposure to open-fire cooking and the cognitive performance of 188 3- to 9-year-old children in the four-culture data. Parents were the informants regarding modes of cooking. In two of the communities (Logoli in Kenya; Newars in Nepal), open-fire cooking (with wood, dung, or straw) in indoor spaces was used at all times. In the Samoan community, cooking was done on kerosene stoves, a practice that is less hazardous to child health and, relevant to the present discussion, highly associated with community adoption of other elements found in industrialized societies. In one community, there was intracultural variation: Garifuna families employed different modes of cooking - both open-fire (with wood) and kerosene - and at different levels of frequency.

We found moderate to strong negative relations [Cohen, 1988] between openfire cooking and cognitive performance, with child age controlled. The relations were stronger for younger children, and they remained for all age groups when children's educational levels were introduced as a further control. When we examined these relations intraculturally with the Garifuna families (and controlled as well for socioeconomic status), the patterns generally accorded with those found for the full sample, though they were somewhat less robust. Although these correlational outcomes cannot point directly to any causal mechanisms, our findings are consistent with ideas about open-fire cooking and its negative developmental consequences, especially in the early years [Smith et al., 2004].

\section{Observation of Children's Questions in the Four Communities: Early Differences}

Now we turn to a discussion of one particular aspect of our analysis of the fourculture data [Munroe, Gauvain, \& Beebe, under review]. As noted above, the unschooled 3-year-olds in Samoa and Belize, the two communities with greater presence of amenities common to industrialized societies, outperformed the Nepalese and Kenyan children of the same age. It appears that even before children entered school they were reaping some of the seemingly cognitive benefits of differential societal adoption of these elements. The magnitude of absolute score differences between these two pairs of societies tended to decline for older children, though this was probably due to ceiling effects on the tests as the Nepalese and Kenyan sample children of 7 and 9 years of age gradually approached the top level performances of the Samoan and Belizean older children. If we assume that neonates in all cultural groups have equal potential, then a central research issue is how such cognitive performance differences are inculcated so early. In a later section of this article, we shall point to other data from our study that augment these findings.

One intriguing difference between Western children and those in our four cultures was the use of 'why' questions in ordinary daily interaction. As Chouinard [2007] has shown through analysis of the CHILDES database [MacWhinney \& 
Snow, 1985], almost one quarter of the (information-seeking) questions asked by 3 - to 5 -year-old American children were of this type - that is, questions that sought explanation rather than just isolated factual information. In contrast, 'why' type queries made up fewer than $5 \%$ of the questions asked by the children in our samples. Chouinard argued that a child's use of explanatory questions indicated that learning was taking place, and she carried out experimental work to justify this assertion. That the frequency of 'why' questions differed so much in the four community samples might reflect, we believe, the operation of two factors. The first is that in small-scale traditional societies, including the four we studied, there is an unspoken acceptance of the obviously greater authority of adults vis-à-vis children, especially younger ones [Stephens, 1963]. For a child to often ask 'why' would be to challenge that authority and to appear almost insolent [see LeVine, 1970, for an early instance of this argument]. The second factor is that in these societies children can see for themselves their meaningful part in relatively stable socioeconomic fabrics and therefore seldom need to ask for explanations. As Fortes [1938/1970] observed in his rural African group, 'Nothing in the universe of adult behaviour is hidden from [Tallensi] children or barred to them' (p. 18), and, as he later reported in the same monograph, "I was surprised to note how rarely "why" questions occurred' (p. 40).

In industrialized and postindustrial societies, on the other hand, question-asking (at least in the middle class) [McCarthy, 1930; Tizard \& Hughes, 1984] tends to be regarded as a 'teachable moment,' and the demands of life - new devices and techniques, ever-widening knowledge - make the asking of explanatory type questions a highly adaptive way of coming to terms with its complexity. This approach to the world may fall outside the norms of small-scale traditional societies but, according to Chouinard's findings, it may well contribute to changes in cognitive functioning. As LeVine [2010] has recently phrased it, '[O]ne result of early enculturation is observable "precocity", that is, the emergence of culturally preferred behavior patterns at an age that would be considered extremely early in other cultural contexts' (p. 459). This depiction seems to fit the pattern of explanatory type questioning found in young children in industrialized and postindustrial societies. Its source, as LeVine [2010] implied, is likely to be found in parental behavior. Relevantly, as Harris [2007] described a Western-based finding, 'Mothers who asked more questions had children who asked more questions' (p. 116).

\section{Some Implications of the Findings}

Taken together, our results are consistent with the idea that societal changes that involve the adoption of institutions and amenities common in industrialized societies contribute to certain types of cognitive skills, the same types of skills implicated in the Flynn effect, the documented worldwide increase in IQ since the 1930s [Flynn, $1987,2009]$. What our results showed is that these changes were not only temporal, that is, measurable over time - as Flynn demonstrated - they were also evident at the same point in time when cultures were compared on dimensions regarding these types of cultural changes. Of course, it is not these changes per se that would explain the differences. Rather, adjustments in cognitive activity associated with societal changes register in a range of human activities, including the everyday transactions 
that mature cultural members have with one another and in formal and informal socialization efforts directed toward children. Given our findings across these studies, we concluded that in terms of cognitive development, not all small-scale traditional societies were the same, and the adoption of institutions and other elements common in industrialized and postindustrial societies seemed to have something to do with it.

For us, these results are worth considering in relation to other extant findings. With few exceptions, traditional peoples have done poorly on Western tests of cognitive performance [Munroe \& Gauvain, 2010]. This result holds true even when children are assessed prior to entering school [Callaghan et al., 2011]. The implications of these consistent findings have made Western researchers alert to the risk of bias, and there have been persistent attempts to rationalize the outcomes. The possible reasons advanced for poorer performance by the peoples of small-scale traditional societies have included nonliteracy, unfamiliarity with test materials, emphasis on rote learning, low tolerance of questioning of authority figures, inferior educational levels, toxicity from exposure to carbon monoxide during open-air cooking, inexperience with the forms of discourse and modes of representation associated with formal schooling, how to solve a particular problem, and even what a good solution entails. Since the cultural differences have appeared in studies among both children and adults, we shall refer more or less indiscriminately to results and interpretations that apply to any age group.

Interpreted liberally, all the factors listed above have some element of societal change of a particular sort embedded within them. Taken together or in various combinations, they might constitute something approaching a complex explanation, one in which changing environmental conditions contribute in intricate ways to cognitive development. Although this view opens the door to examining how particular types of changes affect cognitive development, it challenges the idea that performance by people living in small-scale traditional societies on Western-based assessments are uniform or can be understood separately from the institutions, tools, and practices of the community. It also stands in contrast to culturally relativistic views taken by numerous writers who claim that there are no valid differences to explain, a topic to which we now turn.

\section{A Claim}

At an early date, Berry [1974] argued that cognitive performance could be measured meaningfully only within a culture group, and not cross-culturally. Berry's 'radical cultural relativism ... requires that indigenous notions of cognitive competence be the sole basis for generation of cross-culturally valid descriptions and assessments of cognitive capacity' (p. 225). This seems to us to be a dodge, for it assumes that, unlike perception [Segall, Campbell, \& Herskovits, 1966], emotion [Ekman, 1973], personality [Rohner \& Rohner, 1975], or social behavior [Whiting \& Whiting, 1975], there can be no valid cross-cultural comparisons of cognition. Similarly, Cole and Bruner [1971] contended that they would 'review a body of data and theory that ... raises doubts as to whether any nonsuperficial [intellectual] differences [italics in original] exist among different cultural groups' (p. 868). And Flynn [1987], despite showing convincingly that there was a massive worldwide increase in 
IQ test scores over the course of the twentieth century [Flynn, 2009, pp. 2-3], has nevertheless concluded that this 'does not mean that intelligence has increased' (p. 186).

Our view on this issue is most closely aligned with that expressed by Mishra [1997] who, in a handbook chapter on cross-cultural cognition, stated, '[W]e can conclude ... that valid inferences about [cognitive] competencies can be drawn only by situating assessment in the broader cultural life of individuals or groups' (p. 156). At a general level, this view has been well established in the research literature: cognitive development is affected by the environmental conditions of a cultural community or social group. In fact, in 1969, Greenfield and Bruner made a case for strong environmental contributions to cognitive performance when they wrote that '[S]ome environments "push" cognitive growth better, earlier, and longer than others' [Greenfield \& Bruner, 1969, p. 654]. Of course, what is better in cognitive performance is relative to the outcome in the context of cultural goals.

We want to make a claim about all the findings. For us, the thrust of the outcomes is real in the sense that, on average, individuals brought up in communities that have adopted institutions and elements, including technology, common in industrial societies have certain cognitive advantages over individuals who have been raised in, and who continue to live in, small-scale traditional societies that have minimal adoptions of these elements. We argue that it is important to understand what these advantages amount to, in terms of both benefits and limits. In proceeding with our claim, we are assuming that the various test results, despite their limitations, are measuring something relevant to cognition. What types of cognitive advantages might exist among individuals reared in industrialized communities as compared with individuals in small-scale traditional societies? We believe that Flynn [2009] did hit the mark in one of his comments on the meaning of increases in IQ scores:

I think that I have made a strong case that IQ gains show an enhanced real-world capacity to view the world through scientific spectacles. I believe I can show that this has enormous potential to alter human cognition ... IQ gains also show that we can attack abstract and visual symbolic problems more successfully and that we are better at on-the-spot problem solving on tasks removed from concrete reality. (pp. 42-43)

Cole and Scribner [1974] made a similar assessment in their evaluation of differential performance on syllogisms: that in traditional groups, the reasoning proceeds from 'evidence that is real and experiential, rather than from the theoretical evidence incorporated in the problem' (p. 162).

Schooler [1998] has located the source of the Flynn effect in environmental complexity, and he is referring to the same class of factors we have discussed. It seems to us ineluctable that individuals living in communities that have adopted some of the institutions and other elements of industrial societies are the carriers of the complexity and that without them the complexity would immediately disappear. As proposed in our earlier study, this type of change 'brings with it a complexity that tends to enhance cognitive functioning, at least cognitive functioning as conceptualized and assessed in Western science' [Gauvain \& Munroe, 2009, p. 1640]. Moreover, this complexity is distributed across community members, an important feature of thinking in industrial and postindustrial societies that we believe represents a crossroad of ontogenesis and sociogenesis in these settings. 
On this point, we think one great advantage possessed by the person living in communities that change in this way is that he or she does understand that there are principles that can be looked up, consulted, and generally relied upon, and implicitly knows that concrete problems can often be solved through abstract reasoning, either by themselves or others. This approach to knowledge is not only embedded in formal schooling but also daily manifested in the operation of the sociocultural system itself. As Flynn [2009] stated, 'Over the last century and a half, science and philosophy have invaded the language of educated people ... by giving them words and phrases that can greatly increase their critical acumen' (p. 146). As a case in point, Flynn [2009], discussing the significance of new concepts, asserted that the concept of 'percentage' 'made its debut into educated usage less than 150 years ago. Its range is almost infinite' (p. 147). Earlier, the introduction of Arabic numerals into 12th-century Europe enabled individuals there for the first time to adopt the now familiar decimal system (a base positional system) and to avoid using cumbersome Roman numerals, which require new symbols as numbers increase in magnitude [Ascher, 1991; Devlin, 2011; Swetz, 1987]. And also, as many individuals in today's society tend to understand, the vast collective knowledge possessed in the postindustrial world system is constantly undergoing both enlargement and a degree of revision, that is, it is subject to change and to continual questioning, processes often available through some mediated form. Here, it is worth noting that the lexicon of industrialized societies now includes a specific term, 'googled', to describe a way of looking up information when one does not know the answer first hand.

Yet, not to misconstrue our claim as one in which some peoples are inherently smarter than others, we suggest there is one area of cognitive functioning where all groups appear to be equal in both competence and performance, and that is in the use of spoken language. Languages, though varying greatly, are all highly complicated, yet all 'normal' individuals learn and readily speak their native tongues. Thus, to us the relevant distinction seems to be that of equal potential versus the degree of realized competence and performance, and that is where, in this context, an invention like writing makes some difference. As Macaulay [2011] has pointed out, even while stressing some of the disadvantages of writing, '[T]he writer has to guard against miscommunication by trying to avoid ambiguity or anything else that might mislead the reader' (p. 164), and 'Written texts are static and durable. If you did not grasp something, you can go back and read it again' (p. 163). In other words, writing and reading amount to an added-on cultural complex, what Tomasello [1999] might call a ratchet effect, a facilitator that enhances individuals' universal capacity for symbolic communication. Despite some crosscultural research indicating that literacy is not necessarily transformative in its effects on cognition [Berry \& Bennett, 1989; Scribner \& Cole, 1981], recent research using magnetic resonance imaging suggests strongly that learning to read, even when literacy is acquired in adulthood, 'entails beneficial modification of cortical maps, including sharpened receptive fields and neuronal tuning curves ...' [Dehaene et al., 2010, p. 1359].

To unpack the claim we are making, it is important to look more deeply at what mechanisms make these changes to culture and cognition possible. We consider these below. 


\section{Explanations of Cognitive Differences across Societies That Differ in Elements Associated with Industrial and Postindustrial Societies}

We first want to expand on what was said in the introduction about our breakdown of the sample into societies that differed in the degree to which they incorporated elements common to industrial and postindustrial societies. We have already noted that in some cases the children in all four communities did behave differently from children in the industrial world, and a dichotomy of traditional versus industrialized societies emerged. In other cases, as we shall see, the children in the two more industrialized subsamples, the Samoans and Garifuna, behaved differently from those in the less industrialized groups, the Newars and Logoli, and in still others (as also seen above with the test scores), the ranking of the children's performance accorded completely with the degree of industrialization in the four communities, from Samoa to Garifuna to Newars to Logoli. In the face of this variability, adoption of elements of industrialized societies might be viewed as an imperfect predictor of children's performance in the realm of cognition, but it is important to recognize that all of these cleavages are consistent with each other, and that it is the evidence itself that leads us to a specific ranking or grouping in one case or another.

\section{Testing and Education}

Our discussion thus far has mostly centered on findings that revolve around the use of tests. In some of the commentary we have presented from the literature, the rejection of any assumption of cross-cultural validating in Western-originated tests was implicit, and it would be easy to find further strong critical scrutiny of that assumption [Cole \& Means, 1982]. A recent textbook has even asserted that '[T] he testing of any groups with a foreign test would be considered invalid' [Berry, Poortinga, Breugelmans, Chasiotis, \& Sam, 2011, p. 144]. We obviously differ with this contention, and one of the most telling considerations is that our tests showed typical agerelated improvements in performance. But beyond our own study, there are investigations like Serpell's [1993], which found that in the developing nation of Zambia, standard intelligence tests predicted performance both at school and work.

Furthermore, one of our tests, dealing with memory for culture-specific activities and employing meaningful props, relied only on familiar objects within each subsample. Thus correct answers, in the form of just performed activities (already known to the children), were available in the setting itself. In all cases, some objects/ activities were 'traditional' (had been extant for generations) and others were due to recent inroads carved by adoption of elements of industrialized societies. For example, Samoan children were presented with one skit involving the weaving of mats (traditional) and another involving a sewing machine (industrialized), and Logoli children were shown the tying of thatch grass (traditional) and the manipulation of a hatband and its subsequent wearing (industrialized). Performance on this memory test was not only associated with industrialized elements, the test itself was among the most strongly intercorrelated with performance on the other cognitive tests.

It must be conceded, nonetheless, that most aspects of tests, including several of those included in our analyses, evidence 'school-like' characteristics. A tester, like a teacher, asks known-answer questions, and the child in Western societies under- 
stands that a correct answer exists and that there are often rules or principles that serve as keys to the answers [Rogoff, Correa-Chávez, \& Cotuc, 2005]. Educated mothers also tend to adopt this convention [Greenfield, 1998]. Clearly children in traditional societies, including our own subsamples where schooling was not part of indigenous life, have less experience with this mode of interaction than do those in modern groups. Without involving ourselves in a detailed response to these issues, we can refer again to the fact that even the unschooled 3-year-olds in the two communities of our subsamples with more elements from industrial societies outperformed the youngest children in the other two communities. Given, however, that formal education did matter, we want to discuss these outcomes but show that both education and the test results were part of a larger set of connections, and that those findings were related to a further pattern of associations with both the children's institutional-level affiliations and their everyday behavior. In all respects, relevance to the children's cognitive functioning can be shown.

As discussed above, formal education, with its accompanying promotion of literacy and numeracy, has often been accorded a special place in attempts to understand the development of cognitive skills. Schooling has sometimes been held up as a 'torch' whereby the assimilation of modern skills is facilitated, patterns of cognitive competency are fostered, and literacy can act as a 'cognitive amplifying tool' [Cole \& Griffin, 1980; Serpell \& Hatano, 1997]. Up to a point, our own data were consistent with this view, as the number of years of schooling (with age controlled) was significantly associated with cognitive performance. Moreover, the older children - 7- and 9 -year-olds - in the Samoan and Garifuna samples were almost completely 'at level' for age, with more than $90 \%$ in line with expected grade achievement, while the majority of Newar and Logoli children were below the expected level. Nevertheless, independently of education, incorporation of elements from industrial societies also predicted cognitive performance. Thus years of schooling helped to account for only part of our test results.

\section{Institutional Arrangements}

It is a truism that national wealth and cognitive ability are interrelated. We do not dispute the directional argument, underpinned by recent research [Rindermann \& Thompson, 2011], that cognitive competence may affect the wealth of nations, but as we have data only for children, we cannot address the issue of causation. Nevertheless, our evidence, to be consistent with a causal model in either direction, should show that the better performing Samoan and Garifuna children were enmeshed in systems where there was more affluence than existed among the Newar and Logoli children. This was the case in two respects. First, the per capita incomes of the nations where the children resided were strongly skewed in favor of the Samoan and Garifuna subsamples, at levels far above those of the Newars and Logoli. Then, more particularly, at least half the sample fathers in the Samoan and Garifuna communities held wage labor positions (e.g., electrician, clerk, driver), but in the other two communities the figure was at $15 \%$ or lower [Gauvain \& Munroe, 2009]. Additionally, in the former two, a few mothers worked as well. As all four communities were small in scale, children whose fathers (or, occasionally, mothers) held wage labor positions would have seen the specific link between family position and the occupation 
of the parent. Although in some ways these data are little more than alternative modes of describing societal change as aligned with industrialized societies, the specific tie to wealth made by some researchers renders the information relevant. Greater access to the artifacts and amenities associated with wealth was of course also exhibited in the items making up our scale of community elements aligned with industrialized societies (e.g., radios, running water), which clearly differentiated between the Samoans and Garifuna, on the one hand, and the Newars and Logoli on the other. In turn, as we have earlier described, better cognitive performance was displayed in the two communities with possession of more of the communicative appurtenances and economically advantageous resources.

Wealth and education appear to have been factors in a sociogenic process that, working systemically, yielded community level differences in cognitive performance across our subsamples. Wealth in a family would have allowed children to experience the benefits of the products of more industrialized settings, such as electrification of the home, and to have at least indirect access to the purchasing power acquired through parents' wages. As to education, its effects are assumed to work not only on the contemporary child but also, in a feedback loop, on a future sociocultural system to which the child will someday be a contributing adult unit. Yet the children within each of the communities were varied in their exposure to these factors, and we have so far only reported test performances as indices of their cognitive competencies. But further sets of quantifiable descriptive data were gathered for all sample children, and they went beyond testing to the use of naturalistic, systematic observations that enabled the codification of molar activities and social behavior. These have been analyzed for what they can reveal in themselves about cognitive functioning, but they also have been compared to the test results to see if consistent outcomes can be discerned.

\section{Children's Behavioral and Social Activities}

To the degree that the tests constituted a standard way of measuring cognitive capability, our approach did not differ from the ordinary cross-cultural study of dependent variables (the tests) and their relation to one or more independent variables (in this case, the elements making up our measure of community alignment with the institutions and accoutrements of industrial societies). But we assume that by interacting with the larger systemic arrangements of which they were a part, the children should also have been influenced in their cognitive functioning in other measurable ways. In an effort to assess such functioning, we have brought to bear the data gathered during observations of the sample children while they were engaged in their normal, everyday activities [Munroe et al., 1997; Munroe \& Munroe, 1990a, 1990b, 1991; Munroe et al., under review]. One of the analyses from these data allowed an estimation of the proportion of activities entailing performance of complex action sequences or, essentially, what could be reliably coded as engagement in symbolic play [Gowdy, Munroe, \& Munroe, 1989]. These types of play included formal and informal games, role-playing, imaginary play, and play with toys, either manufactured or homemade. The overall proportions of such play were much higher in Samoa (19\%) and among Garifuna (17\%) children than in the Newar (6\%) or Logoli (9\%) communities. Of particular interest were significant differences between these 
pairs of subsamples in the level of play with manufactured toys and in the playing of formal games (e.g., card games). In both cases, inspection of the observational protocols makes evident the adoption of material culture from outside the bounds of the traditional society. Another regularity of this sort was the early age at which symbolic play appeared among the Samoans and Garifuna, both the 3-year-olds and the 5 -year-olds averaging two to three times as much engagement in these activities as the Newar and Logoli children. This type of play can be classified on a prima facie basis as evidence of complex cognitive functioning, but it is also meaningful that the play levels for both these age groups were positively and significantly associated with performance on the tests.

A few summary observations about these results appear to be in order. The first is that with a mode of measurement quite different from the tests, we find that children in daily play in the two more industrialized groups were engaging in putatively complex cognitive routines more often than were the children in the less industrialized communities. Second, these routines emerged early, prior to schooling, just as similar early differences appeared in the testing, as reported above. Third, given that the degree to which the younger children did engage in symbolic play was related to their test performances, we believe that the agreement helps justify our contention about the validity of the tests. Fourth, the early emergence of symbolic play at a relatively high level in the two more industrialized of our subsamples matches up with recent cross-cultural findings comparing a Western (Canadian) sample of young children (2- to 3-year-olds) with those from two 'traditional, small-scale' societies (Indian and Peruvian) [Callaghan et al., 2011, p. vii]. Finally, and importantly, the Western artifacts and games, though 'in the environment' of the Samoan and Garifuna children, should to some extent be understood as to their conventional functions, and this must be embedded in the minds of these individuals if these nontraditional elements are to be used. They are not independent of the users, nor the users independent of them.

We want to return briefly to a finding reported in the early part of this paper. Information about question-asking was compiled by a separate series of naturalistic observations devoted to the recording of social interaction [Munroe \& Munroe, 1994], so again the data were independent of the testing (and independent of the observations of daily activities). As noted above, the children in our four cultures, unlike same-aged Western children, hardly asked 'why' questions. Nevertheless, their tendency to ask general information-seeking questions was relatively close to the level at which American children asked such questions. In the USA, the social environment consisted almost entirely of the parents, and the children therefore had no options as to whom they would address a question. In our four cultures, the parents were only a small part of the social scene, and they were frequently absent during observational periods. When they were present, however, they were much more likely to be addressed with a question than were the peers in the scene. And the proportion of the sample children who addressed any questions to parents (either mother or father) coincided with societal rankings based on industrialization, the Samoan children most often, then Garifuna children, followed by Newar children, and then Logoli children. We would direct attention in future cross-cultural research to Harris's [2007] Western-based generalization that children's level of questioning is a function of the number of questions asked by a parent. 


\section{Mechanisms of Societal Change and Cognitive Development}

So far, our paper has been descriptive of differences across small-scale traditional societies that are aligned with shifts in the activity structure and daily life of children and which, in turn, are related to children's cognitive performance. We argue that these shifts coincide with large-scale societal adoption of institutions, including economic and schooling changes, and the technologies and artifacts common in industrial and postindustrial societies. We have not offered explanations or mechanisms as to how these changes in cognition come about, and it is to this topic we now turn.

There seem to be at least three social psychological processes evident in our findings that suggest possible mechanisms. In addition, there are several other ideas for mechanisms implicit in our more general discussion of cognitive functioning in industrialized societies. The social psychological processes we located in our samples include changes to the everyday activities of children, most especially the nature of their play (interactions with peers and other children), their interactions with adults, including conversation, and their participation in formal school. Interestingly, it is the nature of their play and the amount of play that seem especially important, and we note that these patterns are not explained by the time children have available to play. In our sample, the Logoli and Newar children, who lived in the two less industrialized groups, differed sharply in the amount of work they did, with Logoli children working the most of all children in the sample and the Newar children working by far the least.

Regarding other mechanisms that seem evident, at least to us, when we consider cognition as it operates in industrialized societies, there seems to be a willingness, even a need, to distribute cognition across individuals as well as the willingness of community members to take on specialty roles that support the activities of others. This off-loading of the mind, so to speak, opens avenues for all types of learning and thinking that may be less common in small-scale traditional societies where understanding and knowledge as experienced first hand are valued differently. Recall the observations by Luria [1976] among nonliterate Central Asian peasants who did not treat syllogisms as self-contained puzzles containing information and a solution that could be derived from the stated premises. Rather, these participants disagreed with the experimenter about what kind of evidence can be accepted as truth, with the participants insisting that truth is based on first-hand knowledge or, perhaps, the reports of a reliable and experienced person. Luria noted that the nonliterate participants' reasoning was excellent in practical matters, but in the realm of 'theoretical thinking' there were several differences between them and the literate participants who were interviewed. Along these lines, Scribner [1977] suggested that verbal syllogisms represent a specialized language genre that is different from other genres and it is through practice with this genre that individuals become able to handle more complex versions of it and even understand this form of problem. Such experience may be provided in formal school as well as in other societal institutions, such as courts or the marketplace or perhaps even in the songs or rhymes that accompany some types of children's play [Opie \& Opie, 1959].

Despite the cognitive complexity of the industrialized world, the distribution of cognitive skills and knowledge appears largely beneficial, though it can be potentially problematic. Among its benefits is the vast amount of collective knowledge that 
is known and passed across generations. However, the profound distribution of knowledge and perhaps even skill at problem solving in the industrialized world, even among educated and well-employed individuals, may convey a sort of false security. People living in such societies may be one disaster away from being unable to care for themselves and their families, as the 2010 earthquake and tsunami in Japan made frightfully clear. Individuals living in communities that have less reliance on the larger industrial system and more direct control over subsistence may solve problems much better in certain challenging circumstances.

\section{Conclusion}

Our illustrations could be viewed as characterizations of the differences between 'traditional' and 'industrialized' or 'modern' ways of living, but this is not our aim. What we seek is a way of discussing how changes in culture are also changes in cognition (and cognitive development), and we draw on a set of findings available to us as a means of investigating this process. As cultural psychology has shown, one useful way of examining this process is in relation to the activities of the culture and how these activities undergo changes that are aligned with changes to cognition. People living in communities around the world participate in diverse activities - activities through which cognition is formed and expressed - and we have attempted to describe this intricate relation by examining such variations across cultural settings. The rub, of course, is that the cultural changes we studied are neither random nor culturally unique. They are part of a larger and common set of changes that make up the process of globalization. Although we recognize this linkage, we nonetheless strive to examine cultural changes of this sort without imposing greater or more positive value on the 'modern' way of life.

Our account of cultural change process corresponds closely to Pepper's [1961] contextualist view. In his description of hypotheses about the world and how it works, Pepper contrasted the mechanistic and the contextualist worldviews. In a mechanistic worldview, culture determines cognition, whereas in a contextualist worldview, circumstantial and temporal processes of culture are fundamental aspects of human cognition. Pepper described the various worldviews in relation to the basic analogy or root metaphor that underlies the view. For contextualism, the root metaphor is the historic event, which is not conceptualized as something that simply happened in the past. Rather, the historic event is dynamic, evident in the thinking and acting of people. For instance, if a culture practices literacy, there was a time in history when literacy was developed or adopted by the community (though this may have been a period of time and not an event). For literacy to continue as part of the culture (and not as simply a relic or fossil from prior epochs), it needs to be practiced and valued by the members of the culture. In this way, a historical occurrence (a committed engagement in literate practices by a sizable portion of the populace) exists in the behaviors of community members in the present and it is these behaviors that sustain, and transform, this historic event. Such transformations occur microgenetically, ontogenetically, and sociogenetically.

It is also important to stress that the data we use as illustration for our main points were collected from the theoretical framework of cross-cultural psychology and, therefore, the measures we highlight could be deemed to reflect a mechanistic 
world view, to use Pepper's terms. However, there are two points we emphasize on this account. First, we are not using the results to compare the four cultures to determine which culture is smarter (has changed people in a certain way, which would be a mechanistic interpretation). Rather, we are using the information to show that variation on these measures is tied to community differences that reflect different degrees of incorporation or adoption of various appurtenances common in industrial societies. In short, we are using these data to study connections among culture, activity, and cognition because these connections are difficult to study and because it may be increasingly difficult to study these connections as the world 'gets smaller' (or more homogeneous in its artifacts and institutions). Second, the measures were designed to tap cognitive processes using methods that were conventional at the time the data were collected. Some of these measures were used in roughly the same form as they appeared in studies in Western contexts; however, several of the measures were adapted to the local setting. In addition to these more standard measures, we also employed naturalistic observations of children carrying out activities in and around their villages. Altogether, we argue, these data give us insight into how culture, human activity, and cognition operate in mutually informative and creative ways.

We have in numerous places in this essay referred to 'traditional societies' because our claim has been that in cognitive terms the individuals populating these societies can often be classed together and contrasted with persons in the industrial world. For some research problems, it will probably be useful to continue to draw categorical distinctions between the industrialized or industrializing and the traditional. Yet for other areas of cognitive inquiry, such as adept ways to '[deal] with novel problems posed verbally or visually or abstractly' [Flynn, 2009, p. 23], it might be better to choose a sample of societies forming something like a continuum of industrialization. We have described above the utility of several approaches in our single dataset: the ranking of our four-culture communities with respect to the degree of industrialization and children's overall cognitive performance; the characterization of the four communities as a dichotomous pairing of 'more' and 'less' industrialized, and the low level of children's explanatory questions in all four as contrasted with the high rate of Western children's explanatory questions.

Whichever of these approaches is adopted, our recommendation would be to focus on the processes through which the elements of industrialization contribute to and perhaps transform the young child's mind. Due to extensive testing, we know something about industrialization's putative effects, but we know little about the specific adjustments in cognitive activity associated with it. These adjustments must include a range of interactions involving the child, yet they remain somewhat mysterious. In our four-culture study, for instance, the features that regularly increased with community level cognitive scores were the possession, in the home, of writing tablets and books (rank correlation of each with community modernity $=1.00, \mathrm{p}<$ 0.05). How could these items, which would have still been inert for unschooled 3 -year-olds, affect the cognitive performance of very young children? Perhaps literate parents are 'pre-adapting' their children to some of the cognitive benefits of literacy. We do not know, but this again, we suggest, is a rich research area.

A continuing concern in cross-cultural study is 'the differences-as-deficit model' [Herek, 2010, p. 696], which prompted the publication of a recent special section in Perspectives on Psychological Science. In that section, the treatment of cultural dif- 
ferences was addressed by Medin, Bennis, and Chandler [2010], who argued that 'home-field status [taking a particular cultural group as the standard for research] is a serious handicap that pushes researchers toward deficit thinking, however good the researchers' intentions may be' (p. 708). At the conclusion of their article, the authors advise 'actively seeking to use multiple methods comprising a variety of research stimuli with a variety of cultural groups and collaborators' (p. 712).

We hope that readers who consult our original piece [Gauvain \& Munroe, 2009] will agree that we have met these desiderata. (The claim of use of a variety of collaborators will be most clearly seen in our naturalistic observations, where adequate interobserver reliability among local observers was achieved in each cultural group.) We also want to note that in spite of the cautions elaborated by Medin and colleagues, they do make the strong statement that 'there is evidence that even basic cognitive processes may differ across cultures' [Medin et al., 2010, p. 708], which appears to contradict their earlier point. We fully understand the dissonance inherent in examining cultural differences in cognitive performance. So long as cognitive differences across cultures are viewed solely in terms of relative advantage and not as emblematic of important properties of the human mind, including flexibility, responsiveness, and adaptation, serious examination of the contributions of any societal elements that contribute to cognitive development will not occur. This is not to say that some advantages do not exist, but any seeming advantages need to be considered in relation to their function and purpose in a society.

An avoidance of studying changes associated with industrialization is problematic for another reason. Cultural changes, such as those that occur when elements from industrialized societies are incorporated into a community, are not the exception but the rule. Change is a normative feature of culture. Cultures change continuously and one significant source of change is the adoption of new ways of doing conventional things. Some of these new ways emerge from the culture, but many come from cultural contact, a process that is central to globalization.

The process of cultural change resulting from the types of changes we discuss is particularly important to researchers who study cognitive development. Certain characteristics of childhood and the social processes in which children engage as they learn about and participate in culture may operate as wellsprings of cultural change [Gauvain, 2009]. Children's inexperience with the world, the limited nature of their cognition and responsibilities, strivings for autonomy, affinity toward peers, and propensity toward play all provide availability or openness to experiences that are markedly different from the experiences of adults. These characteristics may create opportunities for cultures to change, even radically so, in the brief time span of a generation, and children play a vital, active role in this process [Bjorklund, 2007; Gauvain, 2009].

The idea that the impetus and opportunities for cultural change are built into human psychological development does not mean that any cross-generational changes emerging from these processes are planned or have lasting benefits. The processes that support and guide societal change occur in local situations - in the ways that people interact, the areas of mental functioning that are stressed, and the practices and tools people use. These processes are directed toward the skills and knowledge needed in that setting at that time. Although a change may portend the foreseeable future, and even represent in some way the desired future of the culture [Cole, 1996], the long-range consequences of any specific change are not easy to pre- 
dict and in many instances they may arise gradually and seep into the culture in unexpected ways. Who foresaw that social media such as Facebook, Twitter, and YouTube would help foment the revolutions that swept across North Africa in early 2011, the movements referred to as the Arab Spring?

Societal changes that introduce a cultural community to elements common in industrial and postindustrial societies have consequences for cognitive development because these features change the mind as well as the culture. In other words, widespread changes to the social environment become embodied in the mind through the process of cognitive development. The types of changes we discuss are not unique in this regard, but they do represent a pervasive force and as such it is important to understand how it penetrates cognitive development and, in so doing, helps to change culture itself. Of course, the environmental embodiment is partial and unique to each individual. In our view, the difficult but essential issue is to identify and describe these types of changes without taking an evaluative stance toward the individual or the culture.

One purpose of this essay is to open discourse and study among researchers as to how changes to cognitive development, or ontogenesis, ensue in relation to social changes, or sociogenesis. We highlight changes that align with what has variously been called westernization, industrialization, and modernization, and we stress that this is not a new question: 18th century mathematicians were skeptical of the chalkboard and the consequences it might have on mental calculation and analysis. The question is strikingly familiar today. It is difficult to escape the hand-wringing that accompanies the discussion of how much time children spend using electronic media of one sort or another. Much of this foreboding concerns social consequences, for example, that children may spend too little time playing or socializing with others who are nearby. The cognitive consequences are sometimes considered in a positive light, for example, improved skill at multitasking or mental rotation, and sometimes viewed negatively, for example, shortened attention span. We are interested in framing this debate in broader terms by uniting it with longstanding questions about the connection between cultural practices and cognitive development. To restate, we are concerned with how cultural practices are affected by societal changes associated with the increased incorporation of elements common in industrial and postindustrial societies and how these changes contribute to cognitive development. The more expansive question of how any such changes to cognitive development help recreate culture across generations is also of interest and obviously merits study.

\section{Acknowledgment}

We are grateful to Ronald Macaulay for his comments on an earlier version of this paper.

Cultural Change and Cognitive Development 


\section{References}

Ascher, M. (1991). Ethnomathematics. New York: Chapman \& Hall.

Berry, J.W. (1974). Radical cultural relativism and the concept of intelligence. In J.W. Berry \& P.R. Dasen (Eds.), Culture and cognition (pp. 225-231). London: Methuen.

Berry, J.W., \& Bennett, J. (1989). Syllabic literacy and cognitive performance among the Cree. International Journal of Psychology, 24, 429-450.

Berry, J.W., Poortinga, Y.H., Breugelmans, S.M., Chasiotis, A., \& Sam, D.L. (2011). Cross-cultural psychology (3rd ed.). Cambridge: Cambridge University Press.

Bjorklund, D.F. (2007). Why youth is not wasted on the young: Immaturity in human development. Malden: Blackwell.

Callaghan, T., Moll, H., Rakoczy, H., Warneken, F., Liszkowski, U., Behne, T., \& Tomasello, M. (2011). Early social cognition in three cultural contexts. Monographs of the Society for Research in Child Development, 76 (Serial No. 299), vii-viii, 1-142.

Chouinard, M.M. (2007). Children's questions: A mechanism for cognitive development. Monographs of the Society for Research in Child Development, 72 (Serial No. 286), vii-ix, 1-126.

Cohen, J. (1988). Statistical power analysis for the behavioral sciences (2nd ed.), Hillsdale: Erlbaum.

Cole, M. (1996). Cultural psychology: A once and future discipline. Cambridge: Harvard University Press.

-Cole, M., \& Bruner, J.S. (1971). Cultural differences and inferences about psychological processes. American Psychologist, 26, 867-876.

Cole, M., \& Griffin, P. (1980). Cultural amplifiers reconsidered. In D.R. Olson (Ed.), The social foundations of language and thought (pp. 343-364). New York: Norton.

Cole, M., \& Means, B. (1982). Comparative studies of how people think: An introduction. Cambridge: Harvard University Press.

Cole, M., \& Scribner, S. (1974). Culture and thought. New York: Wiley.

Couperus, J., \& Nelson, C.A. (2006). Early brain development and plasticity. In K. McCartney \& D. Phillips (Eds.), Blackwell handbook of early childhood development (pp. 85-105). Malden: Blackwell Publishing.

Daniels, H., Cole, M., \& Wertsch, J.V. (2007). The Cambridge companion to Vygotsky. Cambridge, England: Cambridge University Press.

Dehaene, S., Pegado, F., Braga, L.W., Ventura, P., Nunes Filho, G., Jobert, A., Dehaene-Lambertz, G., Kolinsky, R., Morais, J., \& Cohen, L. (2010). How learning to read changes the cortical networks for vision and language. Science, 330, 1359-1364.

Devlin, K. (2011). The man of numbers: Fibonacci's arithmetic revolution. New York: Walker \& Company.

Ekman, P. (1973). Cross-cultural studies of facial expressions. In P. Ekman (Ed.), Darwin and facial expression (pp. 169-222). New York: Academic Press.

Flynn, J.R. (1987). Massive IQ gains in 14 nations: What IQ tests really measure. Psychological Bulletin, $101,171-191$.

Flynn, J.R. (2009). What is intelligence? Cambridge: Cambridge University Press (original work published in 2007).

Fortes, M. (1970). Social and psychological aspects of education in Taleland. In J. Middleton (Ed.), From child to adult (pp. 14-74). Garden City: Natural History Press (original work published in 1938).

Gauvain, M. (2009). Social and cultural transitions in cognitive development: A cross-generational view. In A.J. Sameroff (Ed.), The transactional model of development: How children and contexts shape each other (pp. 163-182). Washington: American Psychological Association.

Gauvain, M., \& Munroe, R.L. (2009). Contributions of societal modernity to cognitive development: A comparison of four cultures. Child Development, 80, 1628-1642.

Gauvain, M., \& Perez, S.M. (2007). The socialization of cognition. In J.E. Grusec \& P.D. Hastings (Eds.), Handbook of socialization: Theory and research (pp. 588-613). New York: Guilford.

Gay, J., \& Cole, M. (1967). The new mathematics and an old culture. New York: Holt, Rinehart, and Winston.

Göncü, A., \& Gauvain, M. (2012). Sociocultural approaches to educational psychology: Theory, research, and application. In K. Harris, S. Graham, T. Urdan, C.B. McCormick, G.M. Sinatra, \& J. Sweller (Eds.), APA educational psychology handbook. Vol. 1: Theories, constructs, and critical issues (pp. 123-152). Washington: American Psychological Association.

Gowdy, P.D., Munroe, R.H., \& Munroe, R.L. (1989). Independence of action and measured cognitive performance among children from four cultures. In D.M. Keats, D. Munro, \& L. Mann (Eds.), Heterogeneity in cross-cultural psychology (pp. 382-391). Amsterdam: Swets \& Zeitlinger.

Greenfield, P.M. (1998). The cultural evolution of IQ. In U. Neisser (Ed.), The rising curve: Long-term gains in IQ and related measures (pp. 81-123). Washington: American Psychological Association. 
Greenfield, P.M. (2004). Weaving generations together: Evolving creativity in the Maya of Chiapas. Santa Fe: SAR Press.

Greenfield, P.M., \& Bruner, J.S. (1969). Culture and cognitive growth. In D.A. Goslin (Ed.), Handbook of socialization theory and research (pp. 633-657). Chicago: Rand McNally.

Grusec, J.E., \& Brinker, D.B., Jr. (1972). Reinforcement for imitation as a social learning determinant with implications for sex-role development. Journal of Personality and Social Psychology, 21, 149158.

Harris, P.L. (2007). Commentary. Monographs of the Society for Research in Child Development, 72 (Serial No. 286), 113-120.

Herek, G.M. (2010). Sexual orientation differences as deficits: Science and stigma in the history of American psychology. Perspectives on Psychological Science, 5, 693-699.

John-Steiner, V. (1985). Notebooks of the mind: Explorations of thinking. Albuquerque: University of New Mexico Press.

Kagitçibasi, Ç. (1998). Whatever happened to modernization? Individual modernity with a new name. Cross-Cultural Psychology Bulletin, 32, 8-11.

LeVine, R.A. (1970). Cross-cultural study in child psychology. In P.H. Mussen (Ed.), Carmichael's manual of child psychology. Vol. 2 (3rd ed., pp. 559-612). New York: Wiley.

LeVine, R.A. (2010). Commentary: From the mother's point of view. Ethos, 38, 458-460.

Luria, A.R. (1976). Cognitive development: Its cultural and social foundations. Cambridge: Harvard University Press.

Macaulay, R.K.S. (2011). Seven ways of looking at language. New York: Palgrave Macmillan.

MacWhinney, B., \& Snow, C.E. (1985). The Child Language Data Exchange System (CHILDES). Journal of Child Language, 12, 271-294.

- Masangkay, Z.S., McCluskey, K.A., McIntyre, C.W., Sims-Knight, J., Vaughn, B.E., \& Flavell, J.H. (1974). The early development of inferences about the visual percepts of others. Child Development, 45, 357-366.

McCarthy, D.A. (1930). The language development of the preschool child. Minneapolis: University of Minnesota Press.

McCracken, J.P., Schwartz, J., Bruce, N., Mittleman, M., Ryan, L.M., \& Smith, K.R. (2009). Combining individual- and group-level exposure information: Child carbon monoxide in the Guatemala woodstove randomized control trial (RESPIRE). Epidemiology, 20, 127-136.

-Medin, D., Bennis, W., \& Chandler, M. (2010). Culture and the home-field disadvantage. Perspectives on Psychological Science, 5, 708-713.

Mishra, R.C. (1997). Cognition and cognitive development. In J.W. Berry, P.R. Dasen, \& T.S. Saraswathi (Eds.), Handbook of cross-cultural psychology. Vol. 2 (pp. 143-175). Boston: Allyn and Bacon.

Munroe, R.L., \& Gauvain, M. (2010). The cross-cultural study of children's learning and socialization: A short history. In D.F. Lancy, J. Bock, \& S. Gaskins (Eds.), The anthropology of learning in childhood (pp. 35-63). Walnut Creek: AltaMira.

Munroe, R.L., \& Gauvain, M. (2012). Exposure to open-fire cooking and cognitive performance in children. International Journal of Environmental Health Research, 22, 156-164.

Munroe, R.L., Gauvain, M., \& Beebe, H. (under review). Children's questions in cross-cultural perspective: A four-culture study.

Munroe, R.H., \& Munroe, R.L. (1994). Field observations of behavior as a cross-cultural method. In P.K. Bock (Ed.), Handbook of psychological anthropology (pp. 255-277). Westport, CT: Greenwood.

Munroe, R.H., Munroe, R.L., Shwayder, J.A., \& Arias, G. (1997). Newar time allocation. New Haven HRAF Press.

Munroe, R.L., \& Munroe, R.H. (1990a). Black Carib time allocation. New Haven: HRAF Press.

Munroe, R.L., \& Munroe, R.H. (1990b). Samoan time allocation. New Haven: HRAF Press.

Munroe, R.L., \& Munroe, R.H. (1991). Logoli time allocation. New Haven: HRAF Press.

Munroe, R.L., \& Munroe, R.H. (1994). Cross-cultural human development. Prospect Heights: Waveland.

Nucci, L.P., Saxe, G.B., \& Turiel, E. (Eds.). (2000). Culture, thought, and development. Mahwah: Erlbaum.

Oltman, P.K., Raskin, E., \& Witkin, H.A. (1971). Group Embedded Figures Test. Palo Alto: Consulting Psychologists Press, Inc.

Opie, I., \& Opie, P. (1959). The lore and language of schoolchildren. London: Oxford University Press.

Pepper, S.C. (1961). World hypotheses: A study in evidence. Berkeley: University of California Press.

- Rindermann, H., \& Thompson, J. (2011). Cognitive capitalism: The effect of cognitive ability on wealth, as mediated through scientific achievement and economic freedom. Psychological Science, 22, $754-763$.

Rogoff, B. (2003). The cultural nature of human development. Oxford: Oxford University Press. 
Rogoff, B., Correa-Chávez, M., \& Cotuc, M.N. (2005). A cultural/historical view of schooling in human development. In D.B. Pillemer \& S.H. White (Eds.), Developmental psychology and social change: Research, history, and policy (pp. 225-263). New York: Cambridge University Press.

Rohner, R.P., \& Rohner, E.C. (1975). They love me, they love me not. New Haven: HRAF Press.

Saxe, G.B. (1977). A developmental analysis of notational counting. Child Development, 48, 1512-1520.

Saxe, G.B. (1979). Developmental relations between notational counting and number conservation. Child Development, 50, 180-187.

-Saxe, G.B. (2008). Reflections on J.V. Wertsch's 'From Social Interaction to Higher Psychological Processes', Human Development, 1979. Human Development, 51, 80-89.

- Saxe, G.B., \& Esmonde, I. (2005). Studying cognition in flux: An historical treatment of $f u$ in the shifting structure of Oksapmin mathematics. Mind, Culture, and Activity, 12, 171-225.

Schooler, C. (1998). Environmental complexity and the Flynn effect. In U. Neisser (Ed.), The rising curve: Long-term gains in IQ and related measures (pp. 67-79). Washington: American Psychological Association.

Scribner, S. (1977). Modes of thinking and ways of speaking: Culture and logic reconsidered. In P.N. Johnson-Laird \& P.C. Watson (Eds.), Thinking. Cambridge: Cambridge University Press.

Scribner, S., \& Cole, M. (1981). The psychology of literacy. Cambridge: Harvard University Press.

Segall, M.H., Campbell, D.T., \& Herskovits, M.J. (1966). The influence of culture on visual perception. Indianapolis: Bobbs-Merrill.

Serpell. R. (1979). How specific are perceptual skills? A cross-cultural study of pattern reproduction. British Journal of Psychology, 70, 365-380.

Serpell, R. (1993). The significance of schooling: Life-journeys in an African society. Cambridge: Cambridge University Press.

Serpell, R., \& Hatano, G. (1997). Education, schooling, and literacy. In J.W. Berry, P.R. Dasen, \& T.S. Saraswathi (Eds.), Handbook of cross-cultural psychology. Vol. 2: Basic processes and human development (pp. 339-376). Boston: Allyn \& Bacon.

Slaby, R.G., \& Frey, K.S. (1975). Development of gender constancy and selective attention to same-sex models. Child Development, 46, 849-856.

Smith K.R., Mehta S., \& Maeusezahi-Feuz, M. (2004). Indoor smoke from household solid fuels. In M. Ezzati, A.D. Rodgers, A.D. Lopez, \& C.J.L. Murray (Eds.), Comparative quantification of health risks: Global and regional burden of disease due to selected major risk factors (pp. 1435-1493). Geneva: World Health Organization.

Stephens, W.N. (1963). The family in cross-cultural perspective. New York: Holt, Rinehart and Winston.

-Stevenson, H.W., Parker, T., Wilkinson, A., Bonnevaux, B., \& Gonzalez, M. (1978). Schooling, environment, and cognitive development: A cross-cultural study. Monographs of the Society for Research in Child Development, 43, 1-92.

Swetz, F.J. (1987). Capitalism and arithmetic. LaSalle: Open Court.

Tizard, B., \& Hughes, M. (1984). Young children learning. London: Fontana.

Tomasello, M. (1999). The cultural origins of human cognition. Cambridge: Harvard University Press.

Valsiner, J. (2000). Culture and human development: An introduction. London: Sage.

Vygotsky, L.S. (1987). The collected works of L.S. Vygotsky. Vol. 1: Problems of general psychology (transl. by Norris Minick, edited by R.W. Rieber \& A.S. Carton). New York: Plenum Press.

Wagner, D.A. (1978). Memories of Morocco: The influence of age, schooling, and environment on memory. Cognitive Psychology, 10, 1-28.

Wechsler, D. (1963). Manual for the Wechsler Preschool and Primary Scale of Intelligence. New York: The Psychological Corporation.

Wertsch, J.V. (1979). From social interaction to higher psychological processes: A clarification and application of Vygotsky's theory. Human Development, 22, 1-22.

Wertsch, J.V. (1985). Vygotsky and the social formation of mind. Cambridge: Harvard University Press. Whiting, B.B., \& Whiting, J.W.M. (1975). Children of six cultures. Cambridge: Harvard University Press. 